FACULTY OF ECONOMICS AND APPLIED ECONOMIC SCIENCES

CENTER FOR ECONOMIC STUDIES

ENERGY, TRANSPORT \& ENVIRONMENT

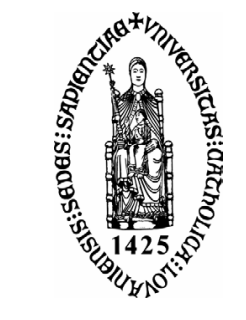

KATHOLIEKE UNIVERSITEIT LEUVEN

WORKING PAPER SERIES

$n^{\circ}$ 2004-03

\title{
Timing of environmental inspections: Survival of the compliant
}

S. Rousseau (K.U.Leuven - CES)

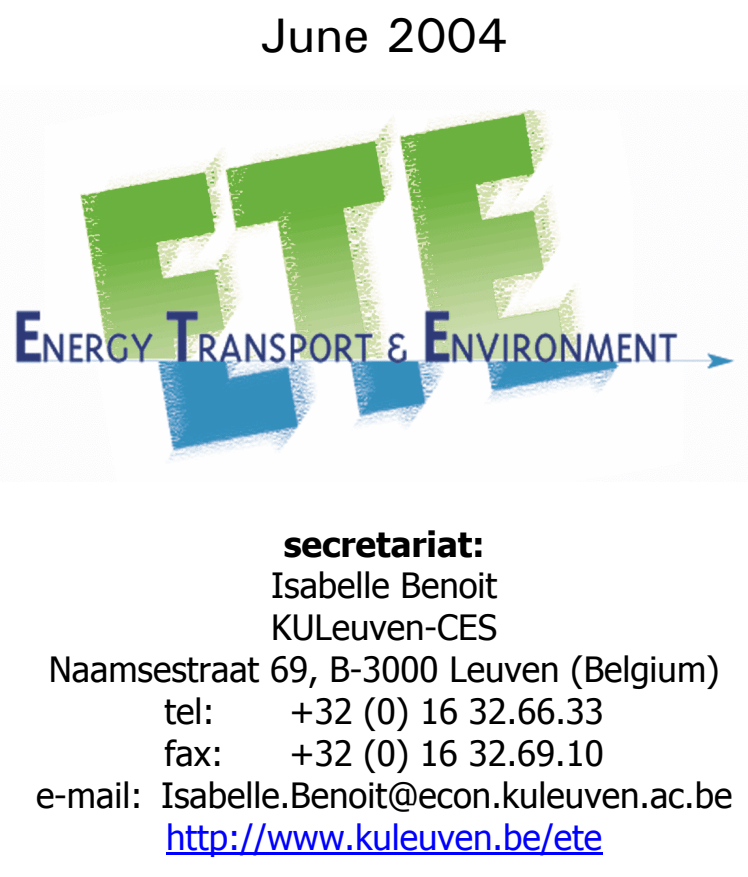




\title{
Timing of environmental inspections:
}

\section{Survival of the compliant ${ }^{1}$}

\author{
Sandra Rousseau
}

June 2004

\author{
Center for Economic Studies \\ K.U.Leuven \\ Naamsestraat 69 \\ B-3000 Leuven \\ Belgium \\ Sandra.Rousseau@econ.kuleuven.ac.be
}

\begin{abstract}
Environmental inspection agencies have limited resources. A natural response to this shortage of resources is targeting. The agency will inspect the firms it suspects to be noncompliant. This targeting policy leads to higher compliance than random inspections. This paper uses individual inspection data on the timing policy of the environmental agency. We focus on the probability that firms in the textile industry in Flanders (Belgium) will be inspected by the environmental inspection agency at a particular moment in time given that the firm was not inspected for $t$ periods prior to that moment. We use a survival model to show that the environmental agency inspects firms in a nonrandom way and investigate the factors that influence the probability of inspection.
\end{abstract}

\footnotetext{
${ }^{1}$ I would like to acknowledge the financial support of the SSTC research program PODO II - contract nr. CP/01/111 (Law \& Economics and the Enforcement of Environmental Law). I would like to thank Carole Billiet, Stef Proost, Peter Schryvers, Laurent Franckx and Geert Dhaene for their useful suggestions. I would also like to thank the Flemish Environmental Inspection Agency (AMI) that helped us greatly to collect the necessary data.
} 


\section{INTRODUCTION}

Environmental inspection agencies have limited resources. On a regular basis we find pleas for more funds and more staff in the media. Within their given budget it is impossible for the environmental agency to inspect all firms on a regular basis. A natural response to this shortage of resources is targeting. The agency will inspect those firms it suspects of being noncompliant with the environmental rules or firms that are major polluters. This targeting policy leads to higher compliance with regulations than random inspections of firms.

One of the first to address this targeting approach of environmental inspections was Harrington (1988). He shows how an enforcement agency can enhance deterrence by dividing regulated firms into two groups according to their past compliance record. The firms are divided into what Harrington labels 'good' firms and 'bad' firms. The environmental agency devotes most of its resources to inspect the firms in the target group or 'bad' group. Therefore, bad firms comply because they wish to be found compliant during an inspection and return to the good firm category. By contrast, good firms can afford to violate the rules because they are infrequently monitored and face low expected penalties. As Friesen (2003) puts it, "the 'stick' of stricter enforcement and the 'carrot' for compliance combine to make stronger incentives to comply than a simple random auditing framework". Subsequent papers have considered the robustness of Harrington's results under asymmetric information (Raymond, 1999), the social optimality implications (Harford, 1991 and Harford and Harrington, 1991), and alternative explanations for high compliance rates such as self-reporting (Livernois and McKenna, 1999) and regulatory dealing (Heyes and Rickman, 1999).

Several empirical papers have estimated the link between past compliance and expected inspections and looked for evidence of targeting. Gray and Deily (1996), for example, use data on individual steel plants to study the relationship between regulator's enforcement of air pollution regulations and firms' compliance decisions in the United States. They find that compliance behaviour influenced enforcement decisions. Steel plants anticipated to be in compliance faced less enforcement, measured either by total enforcement actions or by inspections. Moreover, regulators directed less pressure toward plants expected to close 
and toward plants in attainment areas, while exerting more pressure on plants producing large absolute amounts of pollution, irrespective of their compliance status.

Helland (1998) also provides empirical evidence on the role of targeting in regulatory compliance. He finds that targeting produces more cooperation, in the form of selfreporting, although it does not deter violations. What targeting does, is encourage pulp and paper firms in the US to report violations they detect and presumably take steps to correct them. However, the author concludes that "targeting does little to speed up compliance and is hindered by political factors".

The use of inspections and warnings to enforce environmental regulations is examined by Eckert (2004). The author finds evidence that past warnings increase the probability of an inspection relative to a past finding of non-compliance and that the probability of an inspection decreases with the probability of a violation. Moreover, the paper shows that warnings are used to group Canadian petroleum storage sites according to their compliance history. Warnings can be used as a targeting device and can, therefore, deter future violations through the threat of stronger enforcement.

These empirical papers, however, all use quarterly and, therefore, aggregated data. We state that a substantial amount of information is lost this way. Therefore, we analyse individual inspection data and focus on the length of time that firms in the textile industry in Flanders (Belgium) have to wait before they are inspected by the environmental inspection agency. Given that a firm has not been inspected for $t$ periods, what is the probability that it will be inspected in the next interval of time? If the agency adopts a targeting approach, we can expect the probability that a targeted firm is inspected in the next period to be higher than for a non-targeted firm. We use a survival model ${ }^{2}$ to determine whether firms are inspected in a non-random way and to investigate which aspects influence the probability of inspection. Survival or duration analysis was initially developed to analyse medical data on the duration of life. Over time the applications range

\footnotetext{
${ }^{2}$ Survival analysis was used previously by Nadeau (1997) to model the EPA's effectiveness at reducing the duration of plant-level non-compliance. The results of this paper indicate that the EPA is effective at reducing the non-compliance period of pulp and paper plants. Moreover, Nadeau also shows that the EPA follows separate enforcement strategies based on compliance status; i.e. the EPA uses a targeting approach. However, inspections were estimated as a Poisson process based on quarterly data.
} 
much more widely. Examples include the lifetimes of machine components in industrial reliability, the duration of strikes or periods of unemployment in economics, the lengths of tracks on a photographic plate in particle physics and the survival time of patients in a clinical trial (Cox and Oakes, 1984).

\section{MODEL}

\subsection{State-dependent enforcement or targeting}

The traditional approach on environmental enforcement, derived from Becker (1968), is static. It assumes that a regulator chooses the optimal penalty and probability of inspection for the current period. This implies that a firm will comply with regulation if the cost of doing so is smaller than the expected fine. Thus, increasing the compliance level requires an increase in either the probability of inspection or in the penalty.

Harrington (1988) brings dynamic considerations into the picture and finds that there exists an equilibrium where firms have an incentive to comply with regulations despite the fact that the costs of compliance each period is greater than the expected penalty. As mentioned before, the author divides the firms into two groups on the basis of the firms' past compliance history. In empirical studies this has been translated as targeting that occurs based on the compliance status in the last quarter(s) (see, for example, Stafford (2002)) or on the predicted compliance status of the firm (see, for example, Gray and Deily (1996) or Laplante and Rilstone (1996)). Helland (1998) claims that firms use selfreporting as a costly signal to move from the bad group to the good group. Eckert (2004) shows that the agency uses warnings as a way of targeting firms. However, Friesen (2003) derives the optimal targeting scheme in Harrington's theoretical framework and finds that firms should be moved at random into the targeting group. Escape from the target group occurs only when an inspection reveals the firm is in compliance.

In this model we empirically test whether the Flemish environmental inspection agency (AMI) targets textile firms. Do some firms have a higher probability of being inspected? We investigate which firm characteristics make it more likely that a firm will be inspected. We test several possible variables: compliance status during the previous inspection or during the previous year, was there a notice of violation issued during the previous 
inspection/year, was there a warning issued during the previous inspection/year or did the inspection agency receive a complaint during the previous quarter/year. In the next section we situate the Flemish environmental agency. Afterwards we discuss in detail the factors we expect to influence the agency's inspection decision and the firm's compliance decision.

\subsection{Flemish environmental inspection agency}

The Flemish environmental inspection agency ('Afdeling Milieu-Inspectie' or AMI) is part of the Ministry of the Flemish Region ${ }^{3}$. Its main objective is inspecting and sanctioning polluters in order to improve environmental quality. The agency has several means at its disposal to fulfil this goal. These include several types of monitoring activities: routine inspections, reactive inspections and regulatory projects. Routine inspections involve, for instance, routine sampling of waste water, camera inspections of sewers, checking special conditions in the firm's environmental permit, ad hoc sound measurements and routine sampling of soil and solid waste. Reactive inspections are responses to complaints, calamities, questions of the public prosecutor, parliamentary questions and demands for advice. The regulatory projects are specific monitoring and enforcement campaigns, which are both well-defined in time and in content. They focus on sectors, on problem companies or on a specific pollutant or medium. The AMI planned, among others, the following projects in 2002: integrated control of textile improvement firms, control on the use of ozone depleting substances, emission measurements of burning timber waste and a quality control of acoustic investigations.

Finally, the environmental agency can also use enforcement instruments to protect the environment. It can issue advices, warnings or notices of violations ${ }^{4}$. An advice is given to recommend the firm to make sure that the present situation of compliance with regulations continues in the future. A warning, on the other hand, is provided to instruct the firm to end the present situation of non-compliance and abide with all appropriate laws, decrees

\footnotetext{
${ }^{3}$ Belgium as a federal state consists of three regions: Flanders, Wallonia and Brussels Capital.

${ }^{4}$ The use and definitions of these enforcement instruments can be found in art. 30 of the Environmental Permit Decree and art. 64 of Vlarem I.
} 
and permits. A notice of violation ${ }^{5}$ formally documents a violation and can be used as evidence in a court of law unless the opposite is proven. A copy of this notice of violation is send to the Public Prosecutor. Moreover, the agency can also use administrative sanctions, such as making a motivated proposal to the administration in power to suspend or withdraw the firm's environmental permit.

\subsection{Inspection decision}

We concentrate on water pollution and look at a uniform emission standard, which allows firms to emit no more than $\bar{e}$. We assume that all violations are intentional. There are no accidental violations ${ }^{6}$. Firms are heterogeneous with respect to costs; $\theta$ is a firm-specific, privately observed abatement cost heterogeneity parameter with a continuous distribution $g(\theta)$ between 0 and $\infty$.

The environmental inspection agency randomly inspects a fixed number of firms per year. This fixed probability of inspection is denoted by $\bar{p}_{t}$. We further assume that the inspection agency receives an imperfect signal $r_{i t}$ of the emissions $e_{i t}$ at time $t$ (Heyes, 2002). This signal can be the aggregate measure of complaints, the firm's compliance history or accidental observations. The signal $r_{i t}$ follows a distribution that is singlepeaked at $e_{i t}$ with an associated cumulative $\mathrm{R}\left(r_{t} \mid e_{i t}, H_{i t}\right)$ with $H_{i t}$ a set of exogenous factors, which can be measured in a plant-specific way. The agency audits a firm if the signal $r_{i t}$ is larger than $\Lambda_{t}$. Therefore, the probability of an inspection for firm $i$ at time $t$ is

$$
p_{i t}=\bar{p}_{t}+\left[1-R\left(\Lambda_{t} \mid e_{i t}, H_{i t}\right)\right]
$$

The signal $r_{t}$ can be used to divide firms into two groups depending on the trigger $\Lambda_{t}$. If $r_{i t} \leq \Lambda_{t}$, then the firm belongs to the non-target or 'good' group and faces an inspection

\footnotetext{
${ }^{5}$ Internal regulations of AMI state that the civil servants do not always have to issue a notice of violation when violations are discovered. They have the power to evaluate the situation and use their professional competences to decide on the level of precaution and care displayed by the firm. However, a warning will always be send to the firm if a violation was detected.

${ }^{6}$ Accidental violations will not affect the model as long as they are white noise.
} 
frequency $p_{i t}=\bar{p}_{t}$. If $r_{i t}>\Lambda_{t}$, then the firm is placed in the target or 'bad' group and is inspected with probability $p_{i t}=\bar{p}_{t}+\left[1-R\left(\Lambda_{t} \mid e_{i t}, H_{i t}\right)\right]$.

The agency minimises total environmental damages plus weighted enforcement costs. Principally the agency cares about the environmental damage. The enforcement costs are weighted with $\eta$ the internal marginal cost of expenditure on enforcement (cf. Heyes, 2002). This weight captures the marginal productivity of agency spending in other uses, such as, enforcement programs other than that featured in the model or information programs aimed at firms to point out abatement possibilities and reduce discharges.

The environmental agency has two decision variables: the fixed sampling inspection frequency $\bar{p}_{t}$ and the trigger $\Lambda_{t}$. The objective function of the agency at time $t$ is:

$$
\min _{\bar{p}_{t}, \Lambda_{t}} \int_{0}^{\infty}\left[h\left(e_{i t}^{*}(\theta)\right)+\eta c_{I} p_{i t}\left(e_{i t}^{*}(\theta), \Lambda_{t} ; H_{i t}\right)\right] g(\theta) d \theta
$$

with $h\left(e_{i t}\right)$ the distribution of the harm caused by emissions, $e_{i t}^{*}$ the firm's optimal amount of emissions at time $t$ and $c_{I}$ the cost of an inspection.

The first order conditions for the fixed inspection frequency $\bar{p}_{t}$ and the trigger $\Lambda_{t}$, which determine the variable inspection frequency, are:

$$
\int_{0}^{\infty} \frac{\partial h}{\partial e_{i t}^{*}} \frac{\partial e_{i t}^{*}}{\partial \bar{p}_{t}} g(\theta) d \theta=-\int_{0}^{\infty} \eta c_{I}\left(1-\left.\frac{\partial R}{\partial e_{i t}^{*}} \frac{\partial e_{i t}^{*}}{\partial \bar{p}_{t}}\right|_{H_{i t}}\right) g(\theta) d \theta
$$

and

$$
\int_{0}^{\infty} \frac{\partial h}{\partial e_{i t}^{*}} \frac{\partial e_{i t}^{*}}{\partial \Lambda_{t}} g(\theta) d \theta=-\int_{0}^{\infty} \eta c_{I}\left(1-\left.\frac{\partial R}{\partial e_{i t}^{*}} \frac{\partial e_{i t}^{*}}{\partial \Lambda_{t}}\right|_{H_{i t}}\right) g(\theta) d \theta
$$

We obtain the familiar result that the agency will invest in inspections as long as the benefits outweigh the costs. The increase in the probability of an inspection encourages firms to abate more and to emit less. This implies that the expected environmental harm will decrease. The number of firms with a signal $r_{i t}$ higher than the trigger will decrease and the frequency of variable inspections will be smaller. 
For purposes of estimation, the set of exogenous factors $H_{i t}$ and the components of the signal $r_{i t}$ are important. In the next two sessions we describe different factors that can be included in $r_{i t}$ and $H_{i t}$ and investigate how these elements influence the inspection decision of the environmental agency. In line with the empirical and econometric analysis we focus on the textile industry in Flanders.

\section{Components of the signal $r_{i t}$}

The signal is a vector of factors that are not controlled by the firm in the short run. However, they can be changed in the long run. We distinguish several components: the type of firm, the processes used, the number of complaints received, the compliance history and the discharge medium. We discuss these factors in turn.

Firstly, the firms in our sample belong to two subsectors of the textile industry: textile improvement and carpet production. We can expect to see a difference between the two types of firms. The average composition of the waste water discharged by the two sectors (see appendix A) shows that, overall, carpet production tends to be dirtier than textile improvement. It would be reasonable that the environmental agency focuses on the dirtier firms since they can be expected to increase the marginal benefits to the environmental agency $^{7}$. Increasing compliance at those firms will have a higher impact on the environmental quality. The type of processes used by the firms can also influence the level of emissions. Fibre treatment divisions are potentially dirtier while spinning processes are cleaner. Another factor that is closely related to the processes used is the average amount of water used per kilogram of finished textile. The environmental inspection agency might find it beneficial to inspect those firms that emit large amounts of waste water.

The number of complaints by neighbours or concerned parties is also relevant for the inspection agency. Often these complaints give an indication of potential environmental violations. The expected returns for the agency of following up on these complaints and visiting the accused firms can thought to be higher than the returns on random inspections. Indeed, internal regulations of the Flemish inspection agency state that complaints must be followed by a site visit within three months.

\footnotetext{
${ }^{7}$ In this model the environmental inspection agency does not take the compliance costs of firms into account. Its goal is not an efficient allocation of the abatement costs but minimising environmental damages.
} 
The history of a firm's compliance is also of concern to the environmental agency. The agency can perceive the benefits of targeting firms with a poor compliance history to outweigh any increase in costs. As mentioned in the introduction, empirical evidence ${ }^{8}$ has already shown that environmental inspection agencies (in US and Canada) often target firms based on their compliance history.

Finally, it will also be important whether the firms discharge in the sewers or in surface waters (directly or indirectly). Since the effluent disposed in the sewers is carried to water treatment plants, the environmental agency can find it beneficial to target firms that discharge in surface waters. The impact on environmental quality is possibly greater.

\section{Exogenous factors}

The exogenous factors included in $H_{i t}$ are: the size of the firm, the region and regulatory projects.

The size of the firm is also an important factor. This is measured by the turnover. Larger firms potentially produce more pollution and are a likely target for the inspection agency. However, they might be more complex and thus more costly to inspect. Moreover, large firms are usually better informed and have more resources to spend on abatement. The influence of firm size on inspection frequency is, therefore, ambiguous.

The province in which the firms are located can affect the agency's activity level. The provincial offices of the Flemish Environmental Agency (AMI) are sufficiently independent to allow some provinces to monitor and enforce more stringently than others, even though AMI strives to maintain a uniform enforcement policy throughout the Flemish Region. Historically most of the Flemish textile industry has always been located in East and West Flanders. The firms included in our sample are situated in West Flanders (21), East Flanders (18) and Limburg (2).

The inspection agency yearly decides to implement some specific regulatory projects. For example, the project P216 'Integrated audit of textile improvement companies', realised in

\footnotetext{
${ }^{8}$ See, for example, Gray and Deily (1996), Nadeau (1997), Helland (1998) and Eckert (2004).
} 
2002, allowed us to collect our data. During the course of such a project the firms under consideration are inspected more frequently and more thoroughly (see appendix B).

\subsection{Compliance decision}

Firms minimise their expected costs at time $t$. This gives, for each firm $i$ :

$$
\min _{e_{i t}} \theta_{i} c\left(e_{i t}\right)+F_{i t}\left(p_{i t}, f\left(e_{i t}-\bar{e}\right) ; S_{i t}\right)
$$

With $\theta_{i} c\left(e_{i t}\right) \quad=$ cost to comply with emission standard

$\theta_{i} \quad=$ a firm-specific, privately observed cost heterogeneity

parameter with a continuous distribution $g(\theta)$ between 0 and $\infty$

$F_{i t}() \quad=$. expected penalty function for firm $i$ at time $t$, which increases

with the probability of inspection and the fine

$f_{i t}\left(e_{i t}-\bar{e}\right) \quad=$ the fine of an emission violation is an increasing function of the size of the violation

$S_{i t} \quad=$ set of exogenous factors

The first order condition for the firm's emissions is (cf. Sandmo, 2002)

$$
-\theta_{i} c^{\prime}\left(e_{i t}\right)=F_{i t}^{\prime}\left(p_{i t}, f\left(e_{i t}-\bar{e}\right) ; S_{i t}\right) \text {. }
$$

This is the condition for an interior solution. For it to be the optimum the following condition needs to be fulfilled

$$
-\theta_{i} \frac{d c(\bar{e})}{d e}>\left.F_{i t}^{\prime}\right|_{e_{i t}=0}
$$

We denote the optimal amount of emissions by $e_{i t}^{*}\left(\bar{p}_{t}, \Lambda_{t}, f_{i t} ; S_{i t}\right)$.

For purposes of estimation, the set of exogenous factors $S_{i t}$ is important. Again we concentrate on the textile industry and discuss in the next section the exogenous factors that influence the compliance decisions of the firm. We also predict the signs we can expect in the empirical exercise. 


\section{Exogenous factors}

The number of inspections in the firm under consideration in the previous year can influence the compliance status of the firm. On the one hand, if recently inspected, firms can expect fewer inspections over the next period. Therefore, they would be less likely to comply. On the other hand, assuming the agency focuses on past violators, firms that were recently caught could expect more inspections in the future. This would imply that they are more likely to comply.

Moreover, the compliance decision of the firm also depends on the regulatory projects performed by inspection agency. These projects often include more stringent and thorough inspections. Therefore, the agency is more likely to find violations. For instance, most textile companies in the sample could not show the necessary fire safety reports when asked during the P216-inspections and several of firms needed minor adaptations of their environmental permit to reflect reality better.

Compliance with the emission limits described in the environmental permit (the original one or modification permits) is checked by the environmental agency if these conditions differ from the ones stated in the regulations. Firms know this and expect an inspection if they renew their environmental permit. Consequently, they will try to comply better.

The Flemish Environmental Agency ('Vlaamse MilieuMaatschappij' or VMM) regularly measures firms' emissions in order to determine the effluent taxes the firm need to pay. Firms know that the inspection agency could drop by if the Flemish environmental agency comes to measure emissions. AMI regularly checks the seals on the sampling equipment and ascertains that no fraud occurs. Firms will, therefore, be more likely to comply ${ }^{9}$.

The two types of firm, textile improvement and carpet production, can also have different compliance behaviour. Compliance can depend on the types of divisions present. Dirtier

\footnotetext{
${ }^{9}$ The inspections performed by AMI can have an impact on compliance with measurement regulations. Moreover, we can expect to find less visible signs (such as oil spills or improperly stored chemicals) of possible environmental violations. Compliance with the emission norms for waste water will, however, not be greatly enhanced by these inspections.
} 
firms, for instance, those including a finishing ${ }^{10}$ department, are less likely to comply. Firms that use lots of water are potentially larger violators ${ }^{11}$.

Some firms employ an environmental coordinator. This coordinator is assumed to have a more complete grasp on the environmental situation of the firm. He/she gathers information about the composition and size of the firm's emissions, the processes and the abatement possibilities. This implies that firms with an environmental coordinator should violate less.

Next the way of waste disposal, discharge in sewers versus discharge in surface waters, can have an influence on the firm's compliance decision. Maybe the attitude of firms is more relaxed if they know their waste water will be treated again in a purification station.

Large firms (turnover) have more resources to invest in abatement. Moreover, they can experience economies of scale in emission reduction. This leads us to anticipate larger firms to comply more. However, larger firms usually emit more and the production processes can be quite complex. They can also devote more resources to lobbying and even corruption. This would lead to less compliance.

Finally, it is possible that firms in a particular province are more or less compliant than in other provinces.

\section{ECONOMETRIC METHODOLOGY}

Survival analysis is used to make inferences about the length of time between two environmental inspections. In a survival model we estimate the probability of remaining in a particular state for $t$ periods. In this paper we are looking at the probability that a firm is inspected by the environmental agency at time $t$, given that it has not been inspected for $t$ periods. This method allows us to make assumptions about how factors, such as past

\footnotetext{
${ }^{10}$ In a finishing department the final treatment of the textile occurs such as making it fire resistant or moth resistant. These treatments involve quite a lot of chemicals.

${ }^{11}$ The textile firms cannot use this water to dilute their waste water since the relevant regulations (art. 5.3.2.4 $\S 3$ of Vlarem II) state that the emission limits are linked to a reference volume of waste water (see appendix 5.3.2 of Vlarem II).
} 
compliance behaviour, affect the probability of being inspected. If the firm's past compliance behaviour significantly increases the audit probability, we can say that the agency uses targeting to select firms for an environmental audit.

Let the spell length, or the time between two inspections, be represented by the random variable $T$. Suppose that $T$ has a continuous distribution $f(t)$ and cumulative $F(t)$, where $t$ is a realisation of $T$.

The probability that the spell is of length $t$ or larger is given by the survival function

$$
S(t)=1-F(t)=\operatorname{prob}(T \geq t)
$$

Next we consider the hazard rate

$$
\lambda(t)=\frac{f(t)}{S(t)} .
$$

Roughly, the hazard rate is the rate at which spells are completed after duration $t$, given that they last at least until $t$. In our model the hazard rate represents the probability with which firms are inspected after not being inspected for $t$ periods.

We follow Cox's (1972) approach to the proportional hazard model ${ }^{12}$ to analyse the effect of covariates on the hazard rate. The model (this exposition is based on Greene, 2000) specifies that

$$
\lambda\left(t_{i}\right)=e^{-\beta^{\prime} x_{i}} \lambda_{0}\left(t_{i}\right)
$$

The function $\lambda_{0}$ is the 'baseline' hazard, which is the individual heterogeneity. In principle, this hazard is a parameter for each observation that must be estimated. Let $x$ be a set of regressors ${ }^{13}$ that explain the length of time until inspection. These equal the set of exogenous factors $H_{i t}$ and the determinants of the signal $r_{i t}$ described in section II.2.

\footnotetext{
${ }^{12}$ For a more detailed exposition on proportional hazard models see Cox and Oakes (1984) or Lancaster (1990).

${ }^{13}$ Regressors or covariates are naturally introduced as conditioning variables in the hazard. This poses no problem even when the covariates are endogenously time-varying, as long as the hazard at $t$ is conditioned only on variables that are known at $t$. The situation where some of the explanatory variables depend on time,
} 
Cox's partial likelihood estimator provides a method of estimating $\beta$ without requiring estimation of $\lambda_{0}$. Suppose that the sample contains $K$ distinct exit or inspection times, $T_{1}, \ldots, T_{K}$. For any time $T_{i}$, the risk set, denoted $R_{i}$, consists of all firms whose exit time is at least $T_{i}$. The risk set is defined with respect to any moment in time $T$ as the set of firms who have not yet been inspected just prior to that time. For every firm $j$ in risk set $R_{i}$ we have, $t_{j} \geq T_{i}$. The probability that a firm is inspected at time $T_{i}$, given that exactly one firm is inspected at this time, is

$$
\operatorname{Prob}\left[t_{j}=T_{i} \mid \text { risk set } t_{i}\right]=\frac{e^{-\beta^{\prime} x_{i}}}{\sum_{j \in R_{i}} e^{-\beta^{\prime} x_{j}}} .
$$

Thus, the conditioning sweeps out the baseline hazard functions. For the simplest case in which exactly one firm is audited at each distinct exit time and there are no censored observations, the partial log-likelihood is

$$
\ln L=\sum_{i=1}^{K}\left[\beta^{\prime} x_{i}-\sum_{j \in R_{i}} e^{-\beta^{\prime} x_{j}}\right] .
$$

If $m_{i}$ firms are inspected at time $t_{i}$, then the contribution to the log-likelihood is the sum of the terms for each of these firms

$$
\ln L=\sum_{i=1}^{K}\left[\beta^{\prime} \sum_{j \in T_{i}} x_{i}-m_{i} \sum_{j \in R_{i}} e^{-\beta^{\prime} x_{j}}\right] .
$$

A potential problem occurs since the inspection agency and the firms can be viewed as making decisions about enforcement and compliance simultaneously. If not accounted for, this may bias the results of the estimations. We assume that the firms only review their compliance status after an inspection has taken place. In the interval between inspections this compliance status is assumed to stay constant. Moreover, since we do not work with aggregated data, simultaneity is not an issue. We can estimate the compliance function of the firm and the inspection function separately.

implies that the hazard ratio is no longer constant over time. The model is no longer a proportional hazard model and will be referred to as a Cox regression model. 
Since we want to investigate which target variable the inspection agency uses, we also estimate the compliance function of the firm. Firm compliance is estimated by using a probit model. Greene (2000) provides a thorough discussion on how to specify and estimate probit models. The predicted compliance values obtained by this estimation are then used as an instrumental variable for observed past compliance in the survival model. It is, after all, possible that the environmental inspection agency uses such predictions to target inspections.

\section{DATA}

First we describe the dataset we use for the empirical analysis and illustrate some interesting findings. Next some descriptive statistics are given.

\subsection{Description of the data set}

During the summer of 2003 we collected data gathered by the Flemish environmental inspection agency. Within the framework of internal project P216 the AMI performed a complete environmental audit of forty-one textile improvement and carpet production companies. The database contains information about 1800 inspections completed by the environmental inspection agency between 1991 and 2003. Per inspection we gathered data on its characteristics (type, cause and timing) and on its results (violations and enforcement actions).

Two third of the inspections were water related. Water pollution is indeed the main environmental problem for textile companies. We also looked at the cause of the inspection (see figure 1) as stated on the administrative inspection report. The largest part of the inspections was dedicated to take routine water samples. Also during the project P216 'Integrated audit of textile improvement companies' several inspections were performed. These inspections, which often included water samples, account for $15 \%$ of all inspections included in the database. The project started in 2001 and ended in 2003. Moreover, AMI often receives complaints about firms included in the sample. It is standard policy to follow-up on these complaints within three months and to pay the firm in question a visit. In our sample $13 \%$ of the inspections were triggered by complaints. 
Furthermore the administration inspected firms to follow-up on advices and warnings (7 $\%$ ). Finally, some inspections (7\%) were performed following a request of the headquarters in Brussels (HID) and in their official capacity ${ }^{14}(8 \%)$.

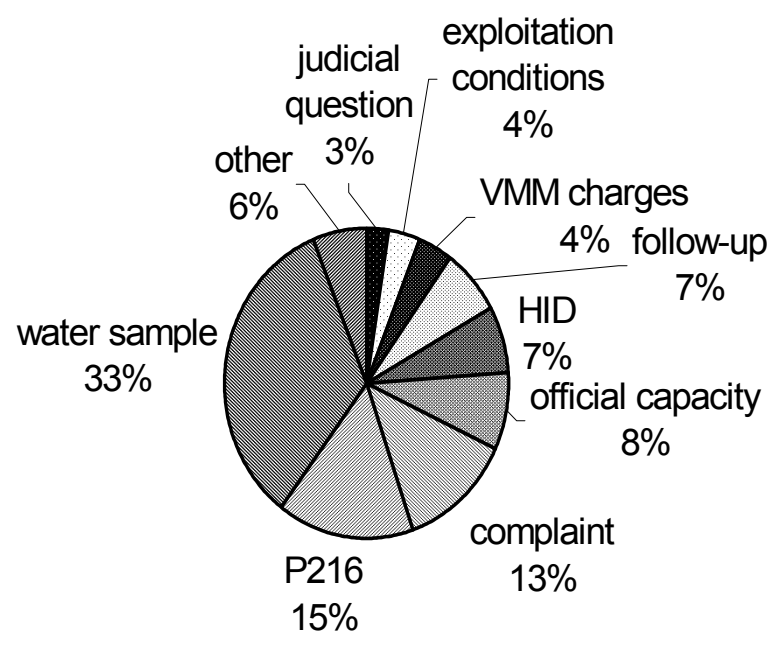

Figure 1 : Causes of inspections

These different types of inspections do not all require the same amount of time. In appendix B we summarise the average duration of an inspection per type. These averages include the time needed to get to the site and back to the office as well as the actual time spend on the firms' premises. Inspections performed to follow-up on VMM measurements and to take routine water samples take just under an hour of the inspectors' time on average. The duration of inspections executed as part of the P216 project, on the other hand, is twice as long. These inspections, as we already mentioned are more thorough. Overall, an inspection took on average 77 minutes.

Next we consider the number of inspections performed per year (see figure 2). The peak in 2002 is clearly due to the project P216. The smaller number of inspections before 1995 is no reflection of reality. For several firms the files were no longer complete. Moreover, in those days the agency did not yet keep its records in an electronic format. Finally, we may

\footnotetext{
${ }^{14}$ Since all inspections are actually performed in their official capacity, AMI has stopped using this terminology. Same goes for the 'HID' inspections.
} 
not forget that the environmental inspection agency (AMI) was only founded in $1991^{15}$ and it took at least two years to get the administration fully functioning.

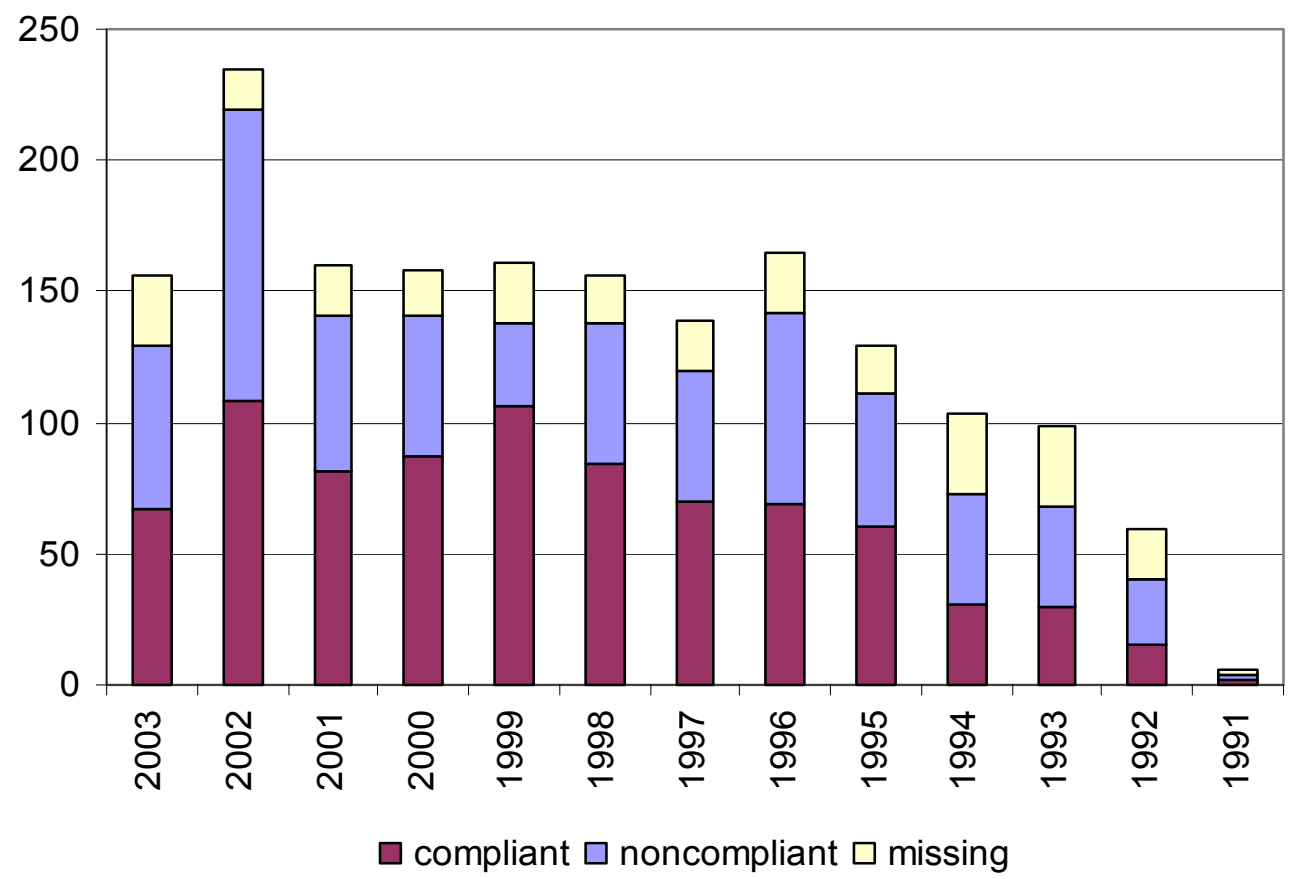

Figure 2: Number of inspections per year and compliance status

We now look at the compliance status of the firms during the inspections. We found that over the years at least $25 \%$ (1992) and at most $66 \%$ (1999) of the firms were compliant. Over the complete database we found that $47 \%$ of the firms were found to be compliant during an inspection.

The violations that were detected include: missing documents such as maintenance reports or fire safety reports, incomplete or missing exploitation license, violations of emission standards for one or more water pollutants, air pollution (gases, smoke and/or bad smell), oil spills and the inaccessibility of the measuring point.

We also look, in figure 3, at the enforcement actions taken after or during an inspection which found a firm in violation. Firstly, we would like to point out that in spite of the many violations we did not encounter administrative sanctions. AMI, for instance, did not

\footnotetext{
${ }^{15}$ Before 1991 only one administration was responsible for both issuing permits and enforcement. Most of its resources, however, were used to deal with permit requests or with modifying them and not with monitoring and enforcement.
} 
send any motivated proposals to the administration in power to suspend or withdraw the firm's environmental permit. These instruments are, however, legally at the disposal of the environmental agency.

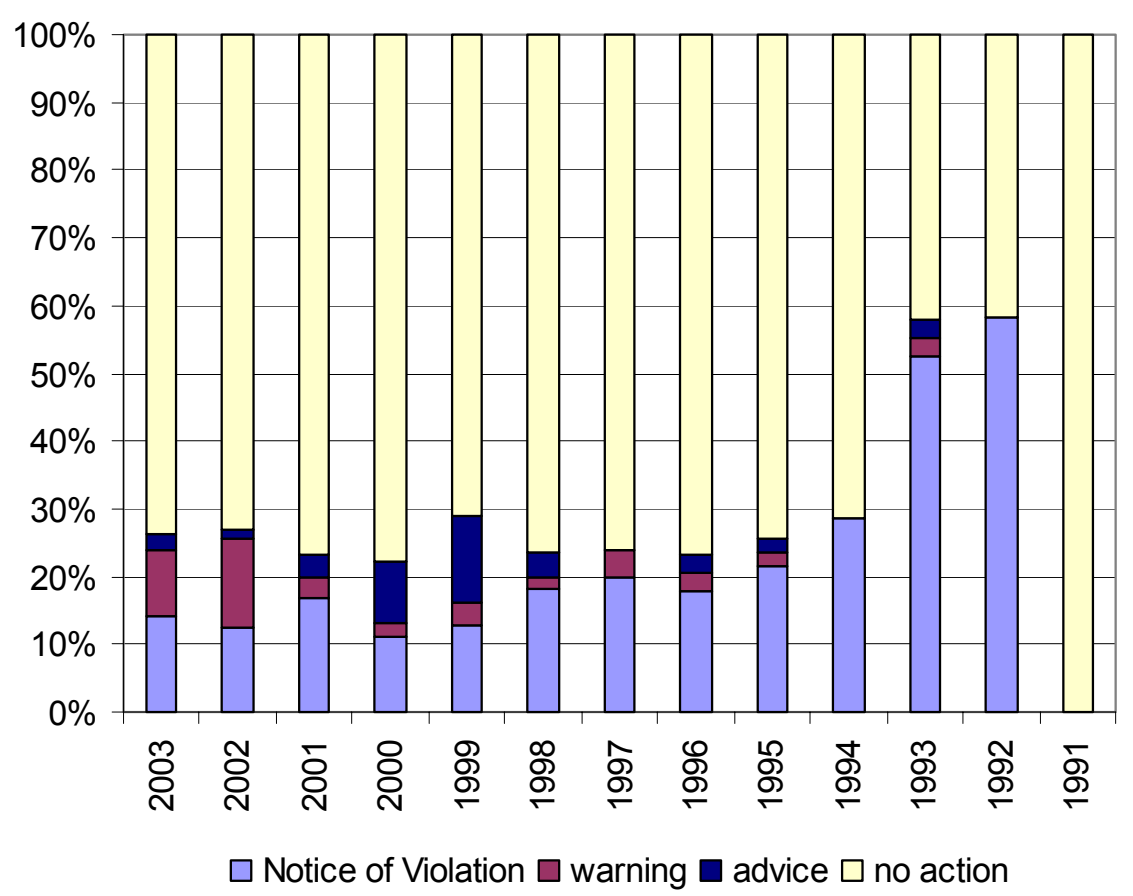

Figure 3: Enforcement action taken after inspection with detected violation

After detecting a violation the inspection agency took some type of enforcement action in 20 to $30 \%$ of the cases. This does not mean that the agency only reacts to 20 or $30 \%$ of total violations. After all, it might take several visits - during which the firm is in violation - to formally prove the violations. For example:

Visit 1: water sample 1 taken

Visit 2: results sample 1 discussed: one or more parameters indicate a violation of less than $100 \%$ and therefore a second water sample ${ }^{16}$ is taken

Visit 3: results of sample 2 are discussed: violation of one or more parameters is confirmed $\Rightarrow$ notice of violation and warning are issued

\footnotetext{
${ }^{16}$ The exact requirements under which such a second sample is necessary can be found in art.4.2.6.1 of Vlarem II.
} 
Also it is quite plausible that after the notice of violation (NOV) accompanied by a warning has been issued, the firm's violation will continue for quite some time. After all, it often takes time to comply. Requesting a new or extended license can take months. Building a new water purification station can even take years. During this period the agency is likely to pay some follow-up visits. During these visits they find the firm in violation (which they already knew) and take no further action (because they already did).

\begin{tabular}{|c|c|c|c|c|c|c|c|}
\hline $\begin{array}{l}\text { Noncompliant } \\
\text { during } \\
\text { inspection }\end{array}$ & \multicolumn{2}{|c|}{$\begin{array}{l}\text { Enforcement } \\
\text { action taken }\end{array}$} & \multicolumn{2}{|c|}{$\begin{array}{l}\text { Information } \\
\text { on follow- } \\
\text { up }^{17}\end{array}$} & \multicolumn{2}{|c|}{$\begin{array}{c}\text { Legal } \\
\text { consequence }\end{array}$} & $\begin{array}{l}\text { Average } \\
\text { monetary } \\
\text { penalty }\end{array}$ \\
\hline \multirow[t]{8}{*}{709} & \multirow[t]{5}{*}{$\mathrm{NOV}$} & \multirow[t]{5}{*}{140} & \multirow[t]{4}{*}{ Info } & \multirow[t]{4}{*}{69} & $\begin{array}{l}\text { Court of } \\
\text { Appeal }\end{array}$ & 2 & 7165 Euro \\
\hline & & & & & First instance & 15 & 2869 Euro \\
\hline & & & & & Settlement & 16 & 260 Euro \\
\hline & & & & & Dismissal & 36 & 0 \\
\hline & & & No info & 71 & & & \\
\hline & Warning & 38 & & & & & 0 \\
\hline & Advice & 21 & & & & & 0 \\
\hline & No action & 510 & & & & & 0 \\
\hline
\end{tabular}

Table 1 : Enforcement of noncompliant firms

In table 1 we analyse what happens after an inspection that found a firm in violation. As mentioned above, in the majority ( $72 \%$ ) of the cases no enforcement action was taken. We concentrate on the notices of violations that are issued since a copy of those is always sent to the Public Prosecutor in order to start legal prosecution. These violations can potentially lead to monetary penalties.

We find that in our sample only 25 percent of the cases (17 out of 69) are actually brought to trial. In 23 percent of the cases (16 out of 69) a settlement is negotiated and the remaining cases $(52 \%)$ are dismissed without further consequences. Looking at the average monetary penalty, we see that the average settlement amount is 260 Euro, the average fine at the first instance is 2869 Euro and the average fine at the Court of Appeal

${ }^{17}$ We process here the information received by AMI on the follow-up on NOVs by the Prosecutor's Office. 
is 7165 Euro. The monetary penalty for violating environmental regulations in Flanders is apparently limited. There must be other motivations for firms to comply with environmental policies. Firstly, firms also have to pay taxes, an effluent fee, depending on the concentrations of pollutants in their waste water. Secondly, textile firms have sizeable incentives to recycle their waste water and to minimise water use during production. These incentives are generated by the tightening of the Flemish groundwater policy. Firms are only allowed to pump up limited amounts (specified in their permit) of groundwater and they have to pay an annual groundwater tax for the water they use. Finally, it is possible that firms are complying in order to avoid bad publicity or because the firm culture is an ethical and environment-friendly one.

\subsection{Descriptive statistics}

In table 2 the different variables used in the estimations are defined. Moreover, we give the expected signs for each of the variables. These expectations are based on the analysis performed in section II.3 and II.4.

\begin{tabular}{|c|c|c|c|c|}
\hline \multirow[t]{2}{*}{ Variable } & \multirow[t]{2}{*}{ Description } & \multirow[t]{2}{*}{ Mean } & \multicolumn{2}{|c|}{ Exp.sign } \\
\hline & & & $\begin{array}{c}\text { Compliance } \\
\text { of firm } \\
\end{array}$ & $\begin{array}{c}\text { Inspections } \\
\text { by agency }\end{array}$ \\
\hline COMPLIANT & $\begin{array}{l}=1 \text { if firm was compliant at } \\
\text { inspection }\end{array}$ & 0.554 & & \\
\hline DURATION & Days between two inspections & 93.380 & & \\
\hline YEAR2002 & Dummy for year 2002 & 0.136 & $\mathrm{n} / \mathrm{a}$ & + \\
\hline INSPYEAR & $\begin{array}{l}\text { Number of inspections in } \\
\text { previous year }\end{array}$ & 4.965 & $?$ & + \\
\hline COMPLAINT & $\begin{array}{l}\text { Dummy if a complaint was } \\
\text { issued against firm }\end{array}$ & 0.145 & $\mathrm{n} / \mathrm{a}$ & + \\
\hline $\mathrm{P} 216$ & Dummy for regulatory project & 0.115 & - & $\mathrm{n} / \mathrm{a}$ \\
\hline PERMIT & $\begin{array}{l}\text { Dummy if conditions in permit } \\
\text { needed testing }\end{array}$ & 0.041 & + & $\mathrm{n} / \mathrm{a}$ \\
\hline VMM & $\begin{array}{l}\text { Dummy if measurements by } \\
\text { VMM needed checking }\end{array}$ & 0.045 & + & $\mathrm{n} / \mathrm{a}$ \\
\hline COMP1 & $\begin{array}{l}=1 \text { if firm was compliant one } \\
\text { inspection ago }\end{array}$ & 0.553 & + & - \\
\hline
\end{tabular}




\begin{tabular}{|c|c|c|c|c|}
\hline COMP2 & $\begin{array}{l}=1 \text { if firm was compliant two } \\
\text { inspections ago }\end{array}$ & 0.551 & + & - \\
\hline COMP3 & $\begin{array}{l}=1 \text { if firm was compliant three } \\
\text { inspections ago }\end{array}$ & 0.551 & $+?$ & $-?$ \\
\hline COMP4 & $\begin{array}{l}=1 \text { if firm was compliant four } \\
\text { inspections ago }\end{array}$ & 0.551 & $+?$ & $-?$ \\
\hline WARNING1 & $\begin{array}{l}=1 \text { if agency issued a warning } \\
\text { one inspection ago }\end{array}$ & 0.021 & + & + \\
\hline NOV1 & $\begin{array}{l}=1 \text { if agency issued NOV one } \\
\text { inspection ago }\end{array}$ & 0.094 & + & + \\
\hline NOV2 & $\begin{array}{l}=1 \text { if agency issued NOV two } \\
\text { inspections ago }\end{array}$ & 0.094 & + & $+?$ \\
\hline ADVICE1 & $\begin{array}{l}=1 \text { if agency gave an advice } \\
\text { one inspection ago }\end{array}$ & 0.014 & + & + \\
\hline IMPROVE & $\begin{array}{l}\text { Dummy for independent textile } \\
\text { improvement firms }\end{array}$ & 0.425 & + & $\mathrm{n} / \mathrm{a}$ \\
\hline INTEGRATED & $\begin{array}{l}\text { Dummy for integrated textile } \\
\text { improvement firms }\end{array}$ & 0.455 & + & $\mathrm{n} / \mathrm{a}$ \\
\hline FIBRE & Dummy for fibre division & 0.085 & $\mathrm{n} / \mathrm{a}$ & + \\
\hline SPINNING & Dummy for spinning division & 0.185 & $\mathrm{n} / \mathrm{a}$ & - \\
\hline FINISH & Dummy for finishing division & 0.746 & - & $\mathrm{n} / \mathrm{a}$ \\
\hline COORDINATOR & $\begin{array}{l}\text { Dummy for environmental } \\
\text { coordinator }\end{array}$ & 0.755 & + & $\mathrm{n} / \mathrm{a}$ \\
\hline SURFACE & $\begin{array}{l}\text { Dummy for discharge in surface } \\
\text { waters }\end{array}$ & 0.380 & + & + \\
\hline USE & $\begin{array}{l}\text { Water use per kg of treated } \\
\text { textile }\end{array}$ & 53.205 & $?$ & $?$ \\
\hline TURNOVER & Firm turnover & 71005 & $?$ & $?$ \\
\hline $\begin{array}{l}\text { WEST } \\
\text { FLANDERS }\end{array}$ & Dummy for West Flanders & 0.473 & $?$ & $?$ \\
\hline
\end{tabular}

n/a : not applicable

Table 2 : Descriptive statistics and expected signs

\section{RESULTS}

\subsection{Compliance function}

Using a probit model we estimate the compliance decision by the firm. The results are given in table 3 . The results are as expected. Firms anticipate the environmental inspection 
if the VMM takes samples of the waste water and are more likely to comply if the inspection was performed to check on the VMM measurements ${ }^{18}$. A firm that was compliant during the last period is more likely to be compliant in the current period. The firms' compliance status seems to be persistent over time. Moreover, the enforcement actions taken by the agency have the desired effect. Issuing a notice of violation or an advice encourages firms to act in accordance with environmental regulations. The presence of an environmental coordinator also has the effect desired by the regulator and induces firms to comply with the rules. Finally, firms, which use more water during their production processes, can more easily dilute their waste water and this leads to less firms found in violation.

\begin{tabular}{|c|c|c|c|}
\hline & & Coefficient & P-value \\
\hline Constant & & -0.368 & 0.2554 \\
\hline INSPYEAR & & -0.0039 & 0.7809 \\
\hline $\mathrm{P} 216$ & $* * *$ & -0.520 & 0.0004 \\
\hline PERMIT & $* * *$ & -0.718 & 0.0024 \\
\hline VMM & $* * *$ & 0.751 & 0.0041 \\
\hline COMP1 & $* * *$ & 0.960 & 0.0000 \\
\hline COMP2 & $*$ & 0.219 & 0.0661 \\
\hline COMP3 & & 0.069 & 0.5481 \\
\hline COMP4 & & 0.130 & 0.1255 \\
\hline WARNING1 & & 0.260 & 0.4140 \\
\hline NOV1 & $*$ & 0.373 & 0.0607 \\
\hline NOV2 & & 0.230 & 0.2706 \\
\hline ADVICE1 & $*$ & 0.633 & 0.0795 \\
\hline IMPROVE & $* * *$ & -0.726 & 0.0000 \\
\hline INTEGRATED & & -0.236 & 0.1207 \\
\hline FINISH & $* * *$ & -0.412 & 0.0090 \\
\hline COORDINATOR & $* *$ & 0.304 & 0.0380 \\
\hline SURFACE & & 0.162 & 0.2622 \\
\hline USE & $* *$ & 0.0043 & 0.0222 \\
\hline
\end{tabular}

${ }^{18}$ The inspections performed by AMI check the compliance with measurement regulations. 


\begin{tabular}{|l|r|r|} 
TURNOVER & -0.0000009 & 0.4532 \\
WEST & 0.057 & 0.6696 \\
FLANDERS & & \\
\hline Log likelihood function $=-434.98$ \\
Restricted log likelihood $=-547.21$ \\
Number of observations $=800$ \\
$* * * / * * / *=$ significant at $1 \% / 5 \% / 10 \%$ level \\
\hline
\end{tabular}

Table 3 : Results for compliance function

We now look at the factors that make it more likely to find a firm violating the rules during an inspection. Again these signs are as expected, except for the variable IMPROVE. The fact that independent improvement companies turn out to be less compliant in our sample, can be explained by the business environment. These companies face severe competition both in Belgium and abroad. This may lead to less attention for environmental issues. Inspections performed as part of the project P216 or to check on permit requirements seem to be more thorough and, therefore, more likely to find the firm in violation with one or more elements of environmental regulations. Moreover, firms that own a finishing department are less compliant.

\subsection{Inspection function}

We now estimate the probability that a textile firm is inspected after not being inspected for $t$ periods (i.e. the hazard rate). The results (see first column of table 4) show that the Flemish inspection agency uses targeting to determine the inspections it will perform. Some firms have a higher probability of being inspected than others.

\begin{tabular}{|l|rrr|rrr|}
\hline & & Coefficient & p-value & Coefficient & p-value \\
\hline INSPYEAR & $* * *$ & 0.137 & 0.0000 & $* * *$ & 0.144 & 0.0000 \\
YEAR2002 & & 0.128 & 0.1564 & 0.139 & 0.1249 \\
COMP1 & $* * *$ & -0.291 & 0.0007 & & & \\
COMP2 & & -0.092 & 0.2820 & & & \\
COMP3 & $*$ & 0.145 & 0.0945 & & &
\end{tabular}




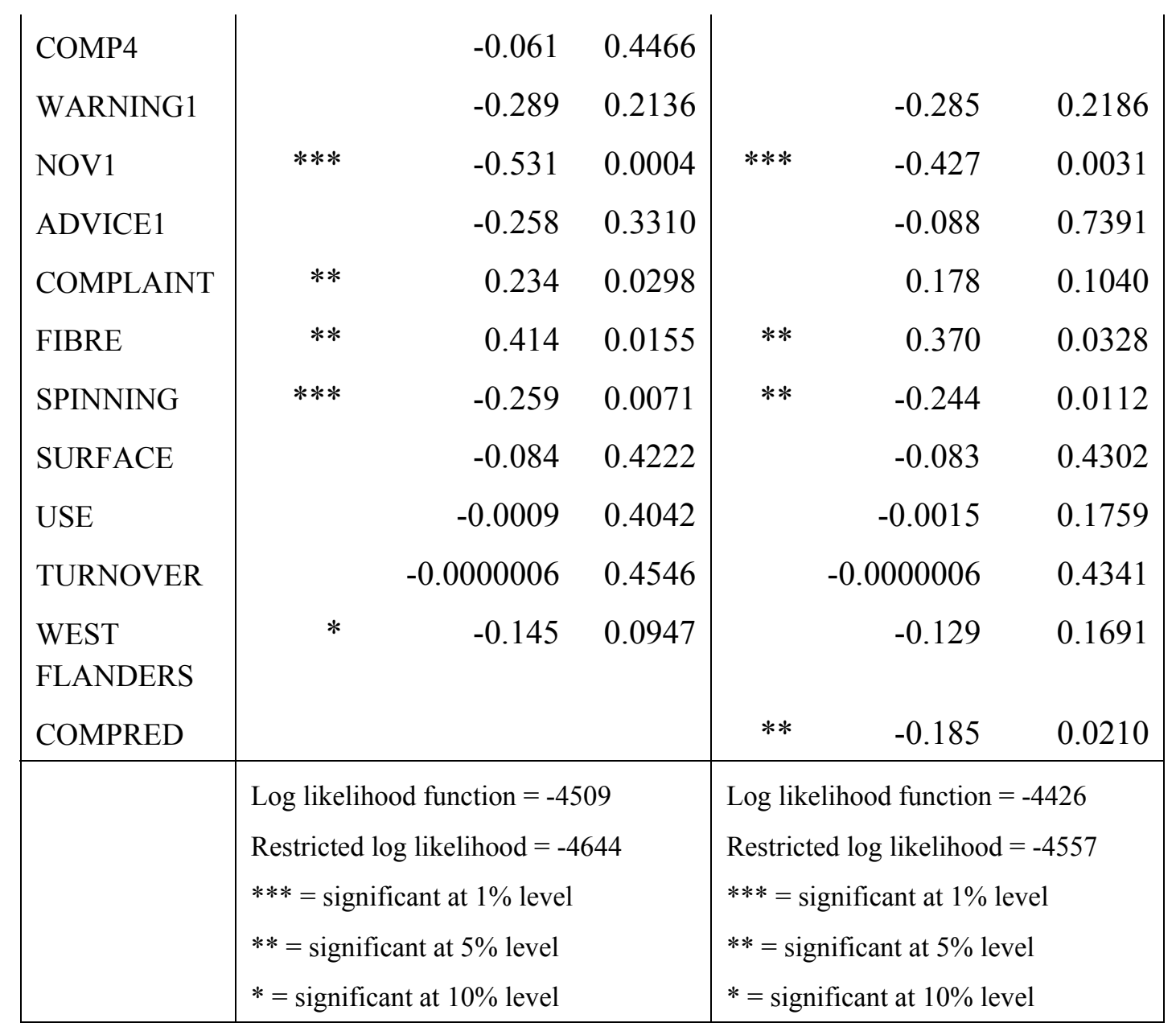

Table 4 : Estimation of probability of inspection

\section{Which are the variables that AMI uses to target its inspections?}

Firstly, the compliance status during the previous inspection (COMP1) influences the probability that a firm will be inspected. Firms that were in violation at their previous inspection are more likely to be audited. This is compatible with Harrington's (1988) analysis. Secondly, firms will be inspected more quickly if a complaint has been issued. Complaints by neighbours, other civil servants or passers-by are always followed up within three months. Thirdly, and this is rather surprising, firms that received a notice of violation during their last inspection, are less likely to be inspected again. However, a closer look at the procedure that starts with a notice of violation clarifies matters. A NOV is always accompanied by a warning. In this warning the agency states the precise nature of the violation and determines a time period during which the firm has to return to compliance. Firms get typically time (three, six, twelve or even more months) to rectify 
the situation depending on the complexity of the corrective measures needed. Within this time frame the environmental agency will not inspect firms to follow up on the violation. The violation is, after all, already detected and legal prosecution has been initiated. As mentioned in table 2 the average time between two inspections is 93 days or 3 months. This explains why we obtain a negative relationship between the probability of being inspected and the fact that firms have received a NOV at their previous inspection. However, other inspections, such as follow-up on complaints, scans for regulatory projects or checking on VMM measurements, will still be effectuated. Contrary to Eckert (2004) our coefficient of the variable WARNING1 is not significant. Therefore, we cannot comment on the use of warnings as targeting variables.

\section{Other determinants of the hazard rate}

The hazard rate or the probability a firm is inspected will increase:

- if the number of inspections in the previous year increase

- $\quad$ if the firm owns a fibre treatment division

Firstly, firms that were already inspected a lot face a higher probability of being audited again. This was not the result we expect at first sight. The variable INPSYEAR probably picks up some firm characteristics that were not included in the analysis but that influence the likelihood of being examined by AMI. Secondly, fibre treatment is a more polluting production process. The agency takes this into account by visiting these firms more often.

The hazard rate will decrease:

- if the firm owns a spinning division

- $\quad$ if the firm is situation in the region West Flanders

A spinning division seems to be a cleaner type of production process than the others. The inspection agency, therefore, seems to inspect these firms less often. Further, the analysis of this particular dataset indicates that firms situated in West Flanders are visited slightly less often than firms in other regions. 


\section{Observed versus predicted compliance}

Next we check whether the probability of an inspection can be better explained by using predicted compliance rather than observed compliance during the previous site visit. Predicted compliance (COMPRED) was calculated using the probit analysis of section V.1. The results in the second column of table 4 show that using predicted compliance instead of observed compliance does not change the results much. The signs of all coefficients remain unchanged and even the levels are approximately the same. However, the significance levels of some estimates change. The coefficient of the region (WEST FLANDERS) and the coefficient measuring the effects of complaints (COMPLAINT) become insignificant.

\section{CONCLUSIONS}

The inspection agency has an important role to play in determining the effectiveness of environmental regulations. Using a limited budget, the agency needs to bring as many firms into compliance as possible. Research has shown that selecting firms based on past behaviour or firm characteristics can greatly increase overall compliance relative to randomly inspecting firms. This monitoring policy is called targeting.

An empirical exercise shows that the Flemish environmental inspection agency (AMI) indeed uses targeting to select the textile firms it will inspect. This selection is based on past compliance behaviour and on complaints received.

Moreover, we find that even though enforcement actions have very little monetary consequences, they still have deterrence effects. Firms are more likely to comply if they received an advice or a notice of violation at their previous inspection. 
APPENDIX A - Average composition of the effluent emitted by carpet production and textile improvement sectors (without treatment)

\begin{tabular}{|lr|r|r|}
\hline Parameter & Unit & Carpet production & Textile improvement \\
\hline Daily load & $\mathrm{m}^{3}$ & 458 & 513 \\
\hline BOD & $\mathrm{mg} / 1$ & 744 & 478 \\
\hline COD & $\mathrm{mg} / 1$ & 2310 & 1475 \\
\hline SS & $\mathrm{mg} / 1$ & 163 & 193 \\
\hline Arsenic & $\mu \mathrm{g} / 1$ & 0 & 2 \\
\hline Silver & $\mu \mathrm{g} / 1$ & 6 & 9 \\
\hline Chromium & $\mu \mathrm{g} / 1$ & 349 & 136 \\
\hline Zinc & $\mu \mathrm{g} / 1$ & 3488 & 593 \\
\hline Copper & $\mu \mathrm{g} / 1$ & 57 & 117 \\
\hline Cadmium & $\mu \mathrm{g} / 1$ & 3 & 2 \\
\hline Lead & $\mu \mathrm{g} / 1$ & 33 & 34 \\
\hline Nickel & $\mu \mathrm{g} / 1$ & 57 & 20 \\
\hline Tot. Nitrogen & $\mathrm{mg} / 1$ & 10 & 32 \\
\hline Tot. Phosphorus & $\mathrm{mg} / 1$ & & 6 \\
\hline
\end{tabular}

Source: Jacobs et al. (1998) 
APPENDIX B - Average duration of the inspections

\begin{tabular}{|c|c|}
\hline $\begin{array}{c}\text { Reason for } \\
\text { inspection }\end{array}$ & $\begin{array}{c}\text { Average duration in } \\
\text { minutes }\end{array}$ \\
\hline VMM charges & 51.37 \\
Water sample & 54.21 \\
HID & 55.32 \\
Complaint & 64.54 \\
Official capacity & 69.21 \\
Follow-up & 79.59 \\
Judicial question & 84.34 \\
Other & 88.44 \\
Exploitation condition & 114.66 \\
P216 & 121.93 \\
\hline Total & $\mathbf{7 6 . 5 4}$ \\
\hline
\end{tabular}




\section{REFERENCES}

Becker, G. (1968). Crime and punishment: an economic approach. Journal of Political Economy, vol.76, p.169-217

Cox, D.R. (1972). Regression models and life tables. Journal of the Royal Statistical Society, vol.B34, p.187-220

Cox, D.R. and Oakes, D. (1984). Analysis of survival data. Chapman \& Hall.

Eckert, H. (2004). Inspections, warnings, and compliance: the case of petroleum storage regulation. Journal of Environmental Economics and Management, vol.47, p.232-259

Friesen, L. (2003). Targeting enforcement to improve compliance with environmental regulations. Journal of Environmental Economics and Management, vol.46, p.72-85

Gray, W. and Deily, M. (1996). Compliance and enforcement: air pollution regulation in the American steel industry. Journal of Environmental Economics and Management, vol.31, p.96-111

Greene, W.H. (2000). Econometric analysis. Prentice Hall. 1004p.

Harford, J.D. (1991). Measurement error and state-dependent pollution control enforcement. Journal of Environmental Economics and Management, vol.21, p.67-81

Harford, J.D. and Harrington, W. (1991). A reconsideration of enforcement leverage when penalties are restricted. Journal of Public Economics, vol.45, p.391-395

Harrington, W. (1988). Enforcement leverage when penalties are restricted. Journal of Public Economics, vol.37, p.29-53

Helland, E. (1998). The enforcement of pollution control laws: inspections, violation and self-reporting. Review of Economics and Statistics, vol.80, p.141-153

Heyes, A. (2002). A theory of filtered enforcement. Journal of Environmental Economics and Management, vol. 43, p.34-46

Heyes, A.G. and Rickman, N. (1999). Regulatory dealing - revisiting the Harrington paradox. Journal of Public Economics, vol.72(3), p.361-378

Jacobs, A., Bettens, L., De Grijse, A. and Dijkmans, R. (1998). Beste Beschikbare Technieken voor de textielveredeling. Academia Press. 
Lancaster, T. (1990). The econometric analysis of transition data. Cambridge University Press.

Laplante, B. and Rilstone, P. (1996). Environmental inspections and emissions of the pulp and paper industry in Quebec. Journal of Environmental Economics and Management, vol.31, p.19-36

Livernois, J. and McKenna, C.J. (1999). Truth or consequences - enforcing pollution standards with self-reporting. Journal of Public Economics, vol.71, p.415-440

Nadeau, L. (1997). EPA effectiveness at reducing the duration of plant-level noncompliance. Journal of Environmental Economics and Management, vol.34, p.54-78

Raymond, M. (1999). Enforcement leverage when penalties are restricted: a reconsideration under asymmetric information. Journal of Public Economics, vol.73, p.289-295

Sandmo, A. (2002). Efficient environmental policy with imperfect compliance. Environmental and Resource Economics, vol. 23 (1), p.85-103

Stafford, S.L. (2002). The effect of punishment on firm compliance with hazardous waste regulations. Journal of Environmental Economics and Management, vol.44, p.290-308 
The Center for Economic Studies (CES) is the research division of the Department of Economics of the Katholieke Universiteit Leuven. The CES research department employs some 100 people. The division Energy, Transport \& Environment (ETE) currently consists of about 15 full time researchers. The general aim of ETE is to apply state of the art economic theory to current policy issues at the Flemish, Belgian and European level. An important asset of ETE is its extensive portfolio of numerical partial and general equilibrium models for the assessment of transport, energy and environmental policies.

\section{ETE WORKING PAPER SERIES 2004}

$n^{\circ} 2004-03$

$n^{\circ} 2004-02$

$n^{\circ} 2004-01$
Rousseau S. (2004), Timing of environmental inspections: Survival of the compliant

Knockaert J., Proost S., Van Regemorter D. (2004), Analysis of transport policy scenarios for EU-countries with PRIMEStransport

Franckx L., de Vries F.P. (2004), Environmental Liability and Organizational Structure

\section{ETE WORKING PAPER SERIES 2003}

$n^{\circ} 2003-19$

$n^{\circ} 2003-18$

$n^{\circ} 2003-17$

$n^{\circ} 2003-16$

$n^{\circ} 2003-15$

$n^{\circ} 2003-14$

$n^{\circ} 2003-13$

$n^{\circ} 2003-12$

$n^{\circ} 2003-11$
Coenen G. (2003), Welfare maximizing emission permit allocations under constraints

Eyckmans J., Finus M. (2003), New Roads to International Environmental Agreements: The Case of Global Warming*

Eyckmans J., Finus M. (2003), Coalition Formation in a Global Warming Game: How the Design of Protocols Affects the Success of Environmental Treaty-Making

Eyckmans J., Schokkaert E. (2003), An "Ideal" Normative Theory for Greenhouse Negociations

Bigano A., Proost S. (2003), The opening of the European electricity market and environmental policy: does the degree of competition matter?

Pepermans G., Willems B. (2003), Regulating transmission in a spatial oligopoly: a numerical illustration for Belgium

Eyckmans J., Pepermans G. (2003), Is er toekomst voor kernenergie in België?

Franckx L. and D'Amato A. (2003), Environmental policy as a multitask principal-agent problem

Proost S. And Van Dender K. (2003), Marginal Social Cost Pricing For All Transport Modes And The Effects Of Modal Budget Constraints 